\title{
CHOREA DUE TO GABAPENTIN MONOTHERAPY IN A NOT ENCEPHALOPATIC PATIENT
}

\author{
Carlos Alexandre Twardowschy', Hélio Afonso Ghizoni Teive ${ }^{2}$, Artur Furlaneto Fernandes ${ }^{1}$ \\ Ismael Paulo Búrigo', Marcos Lange ${ }^{3}$, Lineu César Werneck ${ }^{4}$
}

In the past 10 years the armamentarium of antiepieleptic drugs (AEDs) has almost doubled. With some exceptions, movement disorders are relatively rare in patients using these drugs. In fact, they have become increasingly used to treat some types of movement disorders. Among the newer AEDs, gabapentin was associated with choreoathetosis in several patients in postmarketing reports frequently associated with others AEDs or in patients with encephalopathy ${ }^{1,2}$.

We report the case of a 68-years-old woman, neurologically normal, who developed choreoathetoid movements after gabapentin monotherapy.

\section{CASE}

A 68-year-old hypertensive woman, which reported lumbar pain radiated to the legs associated with paresthesias during the previous 8 months. She used various analgesics without benefit, then she was given gabapentin. Thirty days after the initiation of gabapentin therapy, involuntary choreic movements were noted in her upper and lower limbs. The general physical examination was normal. Neurological examination revealed dysmetria, dysdiadochokinesis, gait ataxia and choreic movements. Cerebrospinal fluid, hemogram, vitamin B12 and ceruloplasmin were all normal. She had no history of chorea in the family. Magnetic resonance imaging showed inespecific microangiopathy in the periventricular white matter in both hemispheres. After the gabapentin withdrawn, chorea reduced gradually in the following week. The clinical diagnostic was gabapentin induced chorea and we did not perform a drug rechallenge. The patient remains living normally, without chorea or ataxia, 6 moths after she stop the drug.

\section{DISCUSSION}

It is important to recognize that movement disorders can occur during treatment with AEDs, particularly in the setting of polypharmacy. Phenytoin is the AED most commonly associated with the development of dyskinesias, particularly chorea, but other convetional AEDs such carbamazepin and valproate have also been implicated. Among the newer AEDs, gabapentin, felbamate and zonisamide have been reported inducing choreic movements ${ }^{3}$.

A temporal relationship was observed in this patient reported between onset and resolution of the involuntary movements and the institution and discontinuation of gabapentin therapy. We did not conduct a drug rechallenge.

The use of gabapentin in conjunction with other standard anticonvulsants in mentally retarded patients may be associated with a significant risk of drug-induced choreoathetosis ${ }^{1,2}$. In a series of 28 gabapentin treated patients as adjunctive therapy for refractory partial seizures, $7.1 \%$ develop choreoathetosis as a result of the treatment ${ }^{1}$.

Differing from the other reports, our case presented no adjuvant therapy. The abnormal movements may be a direct effect of the drug and may not represent a drug interaction like thought.

Another new feature in this case was the absence of prior neurologic deficit. This patient reported had no major damage to the brain structure nor epilepsy. Therefore, patients may not have a prerequisite to the development of this particular side effect.

The mechanism explaining development of chorea with use of gabapentin is unknown. Drug-induced chorea may be severely disabling and many weeks may be required for complete remission of symptoms after the drug withdraw.

\section{REFERENCES}

1. Chudnow RS, Dewey RB Jr, Lawson CR. Choreoathetosis as a side effect of gabapentin therapy in severely neurologically impaired patients. Arch Neurol 1997;54:910-912.

2. Buetefisch CM, Gutierrez A, Gutmann L. Choreoathetotic movements: a possible side effect of gabapentin. Neurology 1996;46:851-852.

3. Factor SA, Lang AE, Weiner WJ. Drug induced movement disorders. $2^{\text {nd }}$ Ed. London: Blackwell 2005:415-417.

\section{CORÉIA RELACIONADA AO USO DE GABAPENTINA EM UM PACIENTE SEM ENCEFALOPATIA}

Neurology Service, Internal Medicine Department, Hospital de Clínicas, Federal University of Paraná, Curitiba PR, Brazil: 'Resident in Neurology; ${ }^{2}$ Adjunct Professor; ${ }^{3}$ Neurologist; ${ }^{4}$ Full Professor.

Received 27 September 2007, received in final form 1 November 2007. Accepted 26 November 2007.

Dr. Carlos Alexandre Twardowschy - Rua Dias da Rocha Filho 261 / 11 - 80040-050 Curitiba PR - Brasil. E-mail: carlos.a.tw@gmail.com 